the meantime, we send reports to the patients, updating them on the progress of the work.

\title{
What is the role of industry?
}

Having a vibrant genomics industry is in the best interests of patients and our community, and of course the total wealth of the country.

We have created a consortium of ten companies ranging from small companies involved in diagnostics or analytics, through to the very large. We have invited those companies into a pre-competitive partnership to look at the first 5,000 genomes with us.

By 'pre-competitive', I mean that they work together, they analyse the data, but they do not own any of the outputs, such as intellectual property. Genomics England owns these on behalf of the UK taxpayer. So if something came up with commercial potential, we would be willing to license that on behalf of the UK taxpayer to third

"The NHS allows us to conjoin academic researchers and the health-care system." parties, thereby creating the potential for the United Kingdom to draw inward investment in terms of realizing the potential of the resource. This also creates a framework for industry to come in and help shape the programme at the outset.

Mark Caulfield is chief scientist at Genomics England, which was set up in 2013 to deliver the UK 100,000 Genomes Project, initially focusing on cancers, rare diseases and infection. Caulfield, a cardiovascular clinician and researcher, spoke about the UK approach to big data in biomedicine and the role of Genomics England - including how it plans to embed genomic medicine in Britain's National Health Service (NHS).

\begin{abstract}
What are the main challenges to integrating genomic medicine into clinical practice?

The first challenge was to establish a platform that provides the capability and capacity to deliver the programme. To that end, we established 11 genomic-medicine centres across England. These are focused groups of clinicians, scientists and academics that enable us to engage patients, enrol them, receive informed consent, and capture clinical data and samples to analyse.
\end{abstract}

Another important issue is how to drive up the quality of the interpretation of those genomes. In partnership with the United Kingdom's innovation agency, Innovate UK, we have spent $£ 10$ million (US $\$ 15.5$ million) of government money on stimulating companies to improve the quality of analysis. In December 2014, we instituted a programme called the Genomics England Clinical Interpretation Partnership (GeCIP), which brings together researchers, clinicians and trainees from both the NHS and academia to improve the analysis of genomic data. The GeCIP covers specific domains. For example, we already have one covering

\section{NATURE.COM}

More on the UK 100,000 Genomes Project here:

go.nature.com/ri9rn5 haematological oncology, which comprises all the people who work on leukaemia and lymphoma in the United Kingdom.

\section{How will your interpretations of the data feed} into the health-care system?

If there is an immediately actionable finding, such as a known pathogenic variation in a patient's genome, we send a clinical report directly to the appropriate NHS Genomic Medicine Centre. Clinicians then look at the data and perform their own validation steps to decide whether they think it is correct, before feeding it back to the patient.

But that decision is always with the NHS. This is about creating a genomically enabled community of people who are looking at this data, are familiar with it, and are 'owning' the decision, as they would in the everyday clinical care of those patients. Embedding this autonomy in the NHS will allow us to build a lasting legacy after the initial Genomics England programme has finished.

If we don't find anything that is obviously pathogenic, those genomes go off to the GeCIP domain relating to that patient's illness. This helps to drive up the accuracy of interpreting genomic information concerning the disease. In
To what extent do you depend on the NHS? Hospitals and universities in the United Kingdom are all part of one NHS, which allows them to work together cohesively and share information freely - something that would not be possible in a highly competitive and fragmented environment. The NHS is a framework that operates at the level of the whole nation, and it is free at the point of delivery. So it makes a huge difference.

The NHS allows us to conjoin academic researchers and the health-care system so that they can respond rapidly to each other's needs - for example, the health-care system can receive requests to collect data and samples in real time and receive results back quickly.

\section{Do you expect this approach to dramatically} speed up research?

It takes an average of 17 years for discoveries to translate from the bench into having a healthcare impact. We are seeking to do this in three years. You maximize your opportunity to do that if you juxtapose the health system and the researchers. For people who fund research, this is a hugely effective and efficient way of doing it.

So I see this as a platform not just for a unique transformation of the UK health-care system, but as a model for health-care systems around the world.

INTERVIEW BY CLAIRE AINSWORTH

This interview has been edited for length and clarity. 